\title{
Incidence of lymphedema in the lower limbs and lymphocyst formation within one year of surgery for endometrial cancer: A prospective longitudinal multicenter study
}

Madelene Wedin, Karin Stalberg, Janusz Marcickiewicz, Eva Ahlner, Asa Akesson, Gabriel Lindahl and Preben Kjölhede

The self-archived postprint version of this journal article is available at Linköping University Institutional Repository (DiVA):

http://urn.kb.se/resolve?urn=urn:nbn:se:liu:diva-170978

N.B.: When citing this work, cite the original publication.

Wedin, M., Stalberg, K., Marcickiewicz, J., Ahlner, E., Akesson, A., Lindahl, G., Kjölhede, P., (2020), Incidence of lymphedema in the lower limbs and lymphocyst formation within one year of surgery for endometrial cancer: A prospective longitudinal multicenter study, Gynecologic Oncology, 159(1), 201208. https://doi.org/10.1016/j.ygyno.2020.07.014

Original publication available at:

https://doi.org/10.1016/j.ygyno.2020.07.014

Copyright: Elsevier

http://www.elsevier.com/

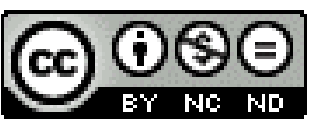




\section{Incidence of lymphedema in the lower limbs and lymphocyst formation}

\section{within one year of surgery for endometrial cancer: A prospective}

\section{longitudinal multicenter study.}

by

${ }^{1}$ Madelene Wedin, MD, (https://orcid.org/0000-0001-9940-4838), ${ }^{2}$ Karin Stålberg, MD, PhD, (https://orcid.org/0000-0001-5527-8796), ${ }^{3}$ Janusz Marcickiewicz, MD, PhD, (https://orcid.org/0000-0001-7512-185X), ${ }^{4}$ Eva Ahlner, RPT, ${ }^{5}$ Åsa Åkesson, MD, (https://orcid.org/ 0000-0002-4938-2869), ${ }^{4}$ Gabriel Lindahl, MD, PhD, (https://orcid.org/0000-0001-9494-1765), ${ }^{1}$ Preben Kjølhede, MD, PhD (https://orcid.org/0000-0001-5702-4116). On behalf of the LASEC study group.

Affiliations:

${ }^{1}$ Department of Obstetrics and Gynecology in Linköping, and Department of Biomedical and Clinical Science. Linköping University, Sweden

${ }^{2}$ Department of Women's and Children's Health, Uppsala University, Uppsala, Sweden

${ }^{3}$ Department of Obstetrics and Gynecology, Varberg Hospital, Varberg, Sweden

${ }^{4}$ Department of Oncology, and Department of Biomedical and Clinical Science. Linköping University, Sweden

${ }^{5}$ Department of Obstetrics and Gynecology, Sahlgrenska University Hospital, and Institute of clinical sciences, Sahlgrenska Academy at the University of Gothenburg, Gothenburg, Sweden

Corresponding author:

Madelene Wedin, MD

Department of Obstetrics and Gynecology University hospital 58185 Linköping

Sweden

Phone : +461030000

E-mail address: Madelene.Wedin@regionostergotland.se 


\begin{abstract}
Objective. The study aimed to determine the incidence of lower limb lymphedema (LLL) after surgery for endometrial cancer (EC) by means of three methods, and to determine the incidence of lymphocysts after one year.
\end{abstract}

Methods: A prospective longitudinal multicenter study was conducted in 14 hospitals in Sweden. Two-hundred-and-thirty-five women with EC were included; 116 underwent surgery that included lymphadenectomy (+LA) and 119 were without lymphadenectomy (-LA). Lymphedema was assessed objectively on four occasions; preoperatively, at 4-6 weeks, six months and one year postoperatively using systematic measurement of leg circumferences, enabling calculation of leg volumes, and a clinical grading of LLL, and subjectively by the patient's perception of lymphedema measured by a lymphedema-specific quality-of-life instrument. Lymphocyst was evaluated by vaginal ultrasonography.

Results After one year the incidence of LLL after increase in leg volume adjusted for body mass index was $15.8 \%$ in +LA women and $3.4 \%$ in -LA women. The corresponding figures for clinical grading were $24.1 \%$ and $11.8 \%$, and for patient-reported perceived LLL $10.7 \%$ and $5.1 \%$. The agreement between the modalities revealed fair to moderate correlation between patient-reported LLL and clinical grading, but poor agreement between volume increase and patient-reported LLL or clinical grading. Lymphocysts were found in $4.3 \%$ after one year.

Conclusions: Although the incidence of LLL and lymphocysts after surgery for EC including LA seemed to be relatively high the study demonstrated significant variations in incidence depending on the measurement modality. This emphasizes the need for a 'gold standard' of measurement of LLL in clinical practice and research.

\title{
Keywords
}

Endometrial cancer; Incidence; Lower limb; Lymphedema; Methodology; Oncology. 


\section{Introduction}

Lymphadenectomy is an important component in the surgical treatment of several gynecological malignancies. The therapeutic significance of lymphadenectomy on prognosis is debated but its role in the surgical staging and consequently its role as a factor in the decision making on adjuvant treatment has been underlined [1-4]. However, lymphadenectomy is associated with increased morbidity, in particular development of lymphedema of the lower limbs (LLL) [5,6]. Lymphedema is a chronic condition that, if untreated, may progress and strongly affects the patient's quality of life $[7,8]$.

Endometrial cancer (EC) is the most common gynecological cancer in Sweden, with an annual incidence of nearly 1500 . Pelvic and para-aortic lymph node dissection is recommended in the primary surgical treatment of apparently early-stage high-risk EC whereas such a recommendation is excluded in low-risk EC $[9,10]$. With an increasing number of survivors after cancer treatment [11] it is important to emphasize the impact of adverse side effects of the treatment as this affects the individual as well as the health care system.

The true incidence of LLL after surgery for EC has not yet been fully established [6]. In the literature, the incidence has been described to vary between $0 \%$ [12] and $50 \%$ [13]. A major concern is that different subjective and objective methods for detecting and measuring lymphedema have been used and are often mixed together [6,8]. In addition, these studies often lack baseline assessments. There are many accepted methods for measuring LLL. These include various clinical evaluations, volume measurement, bioelectrical impedance spectrometry, magnetic resonance imaging and lymphoscintigraphy [14]. However, there is, so far, no international consensus on a 'gold standard' for the method to use for measuring lymphedema in clinical or scientific contexts $[6,8]$. Other adverse effects of pelvic and paraaortic lymphadenectomy (LA) are accumulation of intraabdominal lymphatic ascites and 
lymphocyst formation. These conditions are clinically well known but their incidence and development after surgery for EC are scantily described in the literature $[15,16]$.

So far, important information on the 'true' incidence of LLL, lymphatic ascites and lymphocyst formation after surgical treatment of apparently early-stage EC is lacking. The overall purpose of the present study was to assess the LLL development based on objective and subjective measures and to compare these modes in order to add further knowledge about the care of women with EC.

The primary objective of this study was to determine the incidence of LLL one year after surgery for apparently early-stage EC in women with and without LA using volume measurements, clinical assessment and patient-reported perception of swelling of the legs. Secondary objectives were to evaluate the agreement between the objective and subjective modalities of assessing LLL and to determine the incidence of lymphatic ascites and lymphocysts. 


\section{Material and method}

This is a prospective longitudinal multicenter trial, the 'Lymphedema After Surgery of Endometrial Cancer - trial' (LASEC) conducted at the departments of Obstetrics and Gynecology at four university hospitals, six central hospitals and four county hospitals, and one department of Oncology in Sweden. The study went on between June 2014 and January 2018. The study was registered in ClinicalTrial.gov (ID: NCT02115477; initial release 04/13/2014) and approved by the Regional Ethics Board of Linköping University (Dnr 2013/373-31).

Women with EC admitted to the hospitals for primary surgery were eligible for the study. The women were preoperatively investigated according to the Swedish National Guidelines for EC [10]. The inclusion criteria were: $\geq 18$ years of age, presumed early-stage (FIGO-stage I and II) EC, WHO performance status $<3$, and language proficiency in Swedish. Exclusion criteria were: uterine sarcoma, previous pelvic radiation therapy or pelvic or paraaortic LA, congenital malformation of the lymphatic system or previous treatment of lymphedema, ongoing treatment of arterial or venous insufficiency in the lower limbs, and substantial physical or major mental disability.

After given oral and written informed consent, the patients were examined on four occasions; preoperatively (baseline), after four to six weeks, six months, and one year postoperatively. On all four occasions volume measurements of the legs, clinical grading of swelling of the legs, and gynecological examination including vaginal ultrasonography for detection of lymphatic ascites and lymphocysts were performed. In addition, information about the patient-reported perception of swelling of the legs was retrieved from the lymphedema-specific form, the LYMQOL $[17,18]$ that was filled in by the participants on the same occasions.

Surgical and oncological treatment 
The ECs were categorized preoperatively into low- or high-risk groups according to the Swedish National Guidelines for EC [10]. Low-risk EC was defined as endometrioid carcinoma, FIGO grades 1 and 2, without imaging diagnostic evidence of myometrial invasion exceeding 50\%. EC with myometrial invasion $>50 \%$, endometrioid carcinoma, FIGO grade 3 and non-endometrioid histopathology were classified as high-risk EC. In accordance with the guidelines the low-risk group underwent total hysterectomy, bilateral salpingo-oophorectomy (BSOE) and peritoneal washing, whereas the high-risk group, in addition to the hysterectomy, BSOE and peritoneal washing also had para-aortic and/or pelvic LA and the non-endometrioid EC group also had omentectomy. Postoperative adjuvant treatment and treatment of recurrent disease were given according to the guidelines [10].

\section{Determination of leg volume}

The volume measurements of the legs were conducted according to the cone model described by Sitzia [19]. The leg circumferences (in $\mathrm{mm}$ ) were systematically measured from a fixed point (determined at the baseline measurement as the narrowest part of the lower leg just above the malleolus) to the groin at four $\mathrm{cm}$ intervals. The measurements were entered manually into the software Calculation of Volume of Edema ${ }^{\odot}$ (Wallenius Consulting, Rabeniusvägen 24, 75655 Uppsala, Sweden) that calculated the volume for each leg separately. Volumes were given in milliliter. The changes in volumes between the one-year and baseline measurements were calculated and categorized according to the relative increase in three categories; $<10 \%, 10-20 \%$, and $>20 \%[14,20,21]$. An increase in relative volume $>10 \%$ was considered as LLL.

The measurements were conducted by skilled lymphedema therapists. Preferably, the same therapist should perform the measurements on all occasions. The therapist was blinded to the results of the volume calculation and did not have access to the previous circumference measurement. In order to ascertain the uniformity of the circumference measurements all 
participating lymphedema therapists performed a test-re-test measuring of leg circumferences on a volunteer prior to the start of the study. An external monitor assessed the results of the test-re-tests measurements. To be approved for measuring leg circumferences in the study the deviation in leg volumes between the two measurements of the test-re-test should be less than $10 \%$.

Clinical grading of lymphedema of the legs.

The clinical evaluation and grading of lymphedema in the lower limbs was performed by the lymphedema therapist according to Bruna et al. [22]. The method includes inspection, palpation, effect of elevation of the leg and leg function. The method uses a five-level grading scale, ranging from 0 to 4 . Grade $0=$ all normal, Grade $1=$ pitting edema that disappears with elevation, Grade 2 = discolored skin with pitting edema that decreases with elevation, with slight function disability. Grade 3 = increased skin changes, minimal pitting response, minimal change with elevation and increased function disability. Grade $4=$ increased skin changes with loss of pitting reaction, no response with elevation and significant loss of function. Each leg was assessed separately. The lymph therapist had no access to the results of the previous assessments. Preferably, the same lymph therapist should perform the assessments on all occasions.

Patient-reported perception of swelling of the legs.

To assess the subjective perception of leg swelling the validated Swedish version of the lymphedema-specific quality of life questionnaire LYMQOL [18] that contains a question concerning the perception of swelling of the legs was used. The swelling was graded into four categories graded as 'Not at all'; 'A little'; 'Quite a bit' or 'A lot'. Assessment of lymphatic ascites and lymphocyst formation. 
Vaginal ultrasonography examination was done by skilled gynecologists in conjunction with the gynecological examination at the follow-up visits in order to evaluate the occurrence of lymphatic ascites and encapsulated lymphocysts.

\section{Statistics}

Statistical analyses were performed using the software TIBCO Statistica ${ }^{\mathrm{TM}}$, version 13.5 (TIBCO Software Inc, Palo Alto, CA 94303, USA).

The statistical power analysis determined an estimated sample size of at least 112 women in each group in order to show a significant difference in the size and incidence of LLL between women operated for early-stage EC who are exposed to LA (+LA) and those without LA (-LA) at a 5\% level with $80 \%$ power. This was based on the assumptions that the minimum clinically important difference in increase in volume between baseline and one year, between the two groups was $600 \mathrm{~mL}$ (standard deviation (SD) $1600 \mathrm{~mL}$ ), or the incidence increase between the two groups was $15 \%$ (20\% in the +LA group and $5 \%$ in the LA group.

Continuous data are presented as mean and one $\mathrm{SD}$, and categorical data as number and percentage. Unpaired data were analyzed by means of analysis of variance (ANOVA) or repeated measures ANOVA for normally distributed continuous data and Mann-Whitney Utest for not-normally distributed data. Post hoc tests in the repeated measures ANOVA were analyzed by means of a Tukey honest significant difference test. Categorical data were evaluated by means of Pearson's Chi-squared tests or Fischer's exact tests.

Paired continuous data were examined using Wilcoxon matched pair tests and categorical data were compared using McNemar tests. The categorical data in the paired data comparisons and in agreement estimations were dichotomized.

The correlation between leg volumes and body mass index (BMI) was evaluated by means of Pearson's correlation coefficient. 
Inter-observer concordance of the various modes of measurement of LLL was assessed by means of calculating the observed agreement and Cohen's kappa coefficient that corrects for how often the observed agreement might agree by chance. Interpretation of the kappa values conforms to Landis and Koch [23]; poor for $\kappa=0-0.2$, fair for $\kappa=0.21-0.40$, moderate for $\kappa=0.41-0.60$, good for $\kappa=0.61-0.80$ and very good for $\kappa=0.81-1$. 


\section{Results}

The flowchart (Figure 1) reports the selection of the study population. In total, 235 women completed the study, $116+$ LA and 119 -LA. The demographic and clinical data, subdivided after + LA and - LA, are presented in Table 1 . The peri- and postoperative clinical data and histopathology data are shown in Tables 2 and 3.

\section{Incidence of LLL one year after surgery - by determination of leg volume}

The leg volumes in relation to occasion of measurement and occurrence of lymphadenectomy are presented in Figure 2. The repeated measures ANOVA revealed a statistically significant larger volume of the right and left legs in the -LA group compared with the +LA group $(p<0.001$ and $p<0.01$, respectively). The effect over time analysis showed that this significance was mainly caused by a significant decrease in volume at the 4-6 weeks assessment. Only in the left leg was the volume at the one-year assessment significantly higher than at baseline according to the post hoc tests $(\mathrm{p}<0.01)$. Since BMI was significantly higher in the -LA group compared with the +LA group, and leg volumes on all occasions were strongly positively correlated to BMI (Pearson's correlation coefficients varying between 0.68 and 0.69 ), the leg volumes were adjusted to the mean BMI of the study population on the occasion of measurement. The BMI-standardized leg volumes in relation to occasion of measurement and occurrence of lymphadenectomy are depicted in Figure 3. In the adjusted model, the between group effect in the repeated measures ANOVA was not significant for any of the legs. However, the effect over time was statistically significant in both legs ( $<<0.0001$, in both legs). According to the post hoc tests this was mainly attributed to a significant decrease in leg volume from baseline to the 4-6 weeks assessment ( $p<0.0001$, in both legs), and a significant increase in volume between baseline and the one-year assessment ( $p=0.03$ in the right leg, and $p<0.001$ in the left leg). 
The relative difference in leg volumes between the one-year and baseline assessments in absolute value and as category is shown in Table S1. Except for a significantly higher proportion of $\geq 10 \%$ increase in the BMI-adjusted left leg between the + LA groups, no statistically significant differences were seen between the groups nor within the groups or between the right and left leg.

Based on the BMI-adjusted values, the incidence of LLL one year after surgery in at least one leg was $15.8 \%(18 / 114)$ in +LA women compared with $3.4 \%(4 / 117)$ in -LA women (Pearson's Chi-squared test, $\mathrm{df}=1 ; \mathrm{p}<0.001$ ).

Incidence of LLL one year after surgery - by clinical grading according to Bruna et al. [22] The clinical grading of the groups is presented in Table S2. None of the participants were classified higher than Grade 2 on any occasion. At baseline about 92\% in the +LA group and $89 \%$ in the -LA group were classified as being normal (Grade 0 ). One year after surgery this had dropped statistically significant to about $80 \%$ in the +LA group whereas the drop in the LA group to about $82 \%$ was not significant. No statistically significant differences were seen in the clinical grading between the groups or between the legs on any occasion.

The incidence of de-novo LLL according to the clinical grading in at least one leg was $24.1 \%(26 / 108)$ in +LA women compared with $11.8 \%(13 / 110)$ in the -LA women (Pearson's Chi-squared test, $\mathrm{df}=1 ; \mathrm{p}=0.02$ ).

In order to assess the association between BMI and clinical grading, the BMI was categorized into 'normal weight', 'overweight', and 'obese' according to the WHO's BMIclassification [24]. The results are summarized in TableS3. At baseline, it seemed that there was a significant association between grade of LLL and BMI class for both legs; the higher the BMI class the more frequent was LLL. This effect remained partly at the one-year assessment. It seemed that the obese group was encumbered with more women with a higher grade of LLL. Incidence of LLL one year after surgery - by patient-reported perceived swelling of the legs 
The patient-reported degree of perceived swelling in relation to +LA and -LA is shown in Table S4. At baseline the distribution of the categories of degree of swelling between the +LA and -LA did not differ in both legs, whereas a significantly larger number of women reported swelling in the right leg, but not in the left leg at the one-year assessment. This deviation may be influenced by the fact that significantly more women in the -LA group had swelling in the left leg (24\%) compared with the right leg (16\%) at baseline.

The incidence of de-novo LLL according to the patient-reported perceived swelling in at least one leg was $10.7 \%(12 / 112)$ in + LA women compared with $5.1 \%(6 / 117)$ in the - LA women (Pearson's Chi-squared test, $\mathrm{df}=1 ; \mathrm{p}=0.12$ ).

Table S5 reports the associations between perceived degree of swelling and the BMI classes. It seemed that the perceived degree of swelling was independent of BMI, as no significant associations were obtained.

Agreement between modes of assessment of $L L L$

The agreements between the three modes of evaluating LLL are presented in Table S6-S8 Although high agreements were obtained (between 0.65 and 0.86 ) in all analyses, the kappa analyses showed that the agreement could be classified as fair to moderate ( $\kappa$ values between 0.31 and 0.50 ) only in the comparison of patient's perception of swelling and the clinical grading. Contrarily, the comparison of leg volumes (including BMI-adjusted volumes) and clinical grading and patient's perceived degree of swelling, respectively, demonstrated low $\kappa$ values (below 0.20) indicating poor agreement between these modes of assessment.

\section{Lymphatic ascites and lymphocyst development}

At the 4-6-weeks assessment 42.2\% (49/116) of +LA and 4.2\% (5/119) of -LA presented with lymphatic ascites. Lymphocysts occurred at the same time in $9.6 \%(11 / 116)$ and $0 \%$ (0/119), respectively. One year postoperatively 3.4\% (4/116) in the +LA group had lymphatic ascites accumulation and $4.3 \%(5 / 116)$ had lymphocysts compared with none in the -LA 
group. All women with lymphatic ascites accumulation or lymphocysts were asymptomatic and were treated conservatively. (Table S9). 


\section{Discussion}

The study showed a considerable variation in incidence of LLL one year after lymphadenectomy in high-risk apparently early-stage EC, depending on mode of measurement. The incidence of LLL after lymphadenectomy as measured by the increase in leg volume was $15 \%$, similar to the incidence of patient-perceived LLL (11\%), whereas the incidence of clinically graded LLL was significantly higher (24\%). However, some women with low-risk EC who were not exposed to lymphadenectomy also presented with LLL after one year. These women had a lower incidence, but a similar distribution in relation to the mode of measurements $(3 \%, 5 \%$ and $12 \%$, respectively), compared with the women who underwent lymphadenectomy. Although the observed inter-rater agreements between the assessment modalities in general were high, the Cohens kappa coefficients varied substantially. Only the agreement between clinical grading assessment and patient-perceived LLL was shown by the Cohens kappa coefficient to demonstrate a fair to moderate agreement whereas the agreements between volume increase and clinical assessment, and between volume increase and patient-perceived LLL, respectively, were poor. The incidence of lymphatic ascites and lymphocysts one year after surgery was about $4 \%$, respectively, and seemed to be clinically insignificant.

The incidence of LLL in all assessment modalities found in this study does not fully correspond to what has been previously reported $[5,16,25,26]$. This may be explained by a wide variety in the incidence of lymphedema presented in the literature due to lack of a consensus and a 'gold standard for the method of assessment $[6,8,27]$. However, some of the recent studies using baseline measurements seem to be consistent with our findings in the incidence of leg volume increase [28]. Surprisingly we showed an increase in LLL in both the + LA and the -LA group. This has not previously been systematically explored or described in 
the literature and may be important for the understanding of lymphedema after surgery for EC.

The measuring of leg volumes on several occasions postoperatively gave interesting results, not previously described. The leg volumes decreased significantly at the 4-6 week assessment. The pathophysiological mechanisms behind this phenomenon are unknown, but since the 'the leg volume' is calculated based on circumferential measurements of the leg, and thus composed of intra- and extracellular fluid and tissue (skin, fat, skeletal and muscle tissue), the effect of postoperative catabolism and consequently loss of muscle and fat mass might be a plausible explanation [29] Most likely, the fluid balance has been restored after four to six weeks and consequently does not contribute to the reduction in leg volume.

In the clinical assessment, only a few women developed more severe stages of LLL one year postoperatively. None had higher than Grade 2 and although the + LA group, but not the -LA, increased significantly in clinical grading between baseline and one year postoperatively, no significant difference was seen between the +LA and -LA groups on any occasion. This might indicate that subjective factors play a role in the clinical assessment of lymphedema. As shown for the leg volume assessment, the BMI was strongly correlated to leg volume and consequently it was relevant to adjust the volume for BMI in order to achieve comparable measures [14]. Obesity per se may also induce LLL and thus increase the risk of lymphedema although the pathophysiological mechanism is not fully understood [30-32]. Clearly, the finding in this study showing a significant association between clinical grading and BMI at baseline was interesting and supported the theory of an association between BMI and the development of lymphedema. The association between BMI and clinical grading one year postoperatively was less pronounced and more scattered, most likely caused by a mix of obesity induced lymphedema with the effect of lymphadenectomy on the development of 
lymphedema. This varying relationship raises concerns for assessing incidence of LLL with clinical grading after cancer treatment, in particular in obese women.

The patient's subjective perception of degree of swelling as measured by the LYMQOL $[17,18]$ showed that both the +LA and -LA groups experienced increased swelling one year postoperatively (11\% and 5\%, respectively). These self-reported incidence were low compared with the incidence reported in other studies [25]. Contrary to what has been shown in the arms after breast cancer treatment concerning association between BMI and arm swelling [33], the patient's perception of leg swelling was not associated with BMI. This may imply that information on the patient's perceived swelling, independent of BMI, might be adequate clinically to assess lymphedema after treatment of EC.

To our knowledge, no previous comparison has been published to determine the agreement between different LLL measurement modalities. The low Cohen's kappa coefficients between volume and patient's perception reveals that LLL needs to be addressed from different aspects.

The incidence of persistent lymphatic fluid/ lymphocysts was $7 \%$ one year postoperatively, less than half of what has previously been reported $[15,16,34]$. Lymphocysts might be considered a postoperative complication. However, in this study all lymphocysts were asymptomatic and hence did not cause any essential morbidity. This was in accordance with the previous findings of Salehi et al. [16].

\section{Strengths and limitations.}

The LASEC trial offered many strengths but also some weaknesses. The main strengths were the prospective, longitudinal design using three validated modalities to assess the primary outcome (LLL), the use of a comparison group that was not exposed to the main risk factor for developing LLL (lymphadenectomy), and the study was sufficiently powered. In addition, all the lymphedema therapists who conducted the leg circumference measurements 
were approved after having performed a test-re-test to demonstrate low variation in the measurements. Furthermore, the person that performed the survey was kept blinded to the results of the former measurements, and the trial was conducted according to the guidelines on Good Clinical Practice [35]. The multicenter approach with the geographically widespread locations of the participating hospitals may contribute to the generalizability of the results.

Although the lymphedema therapists were blinded to the results of the former measurements there is always a risk of recall bias. The blinding for the type of surgery, i.e. for whether an LA had been performed, was not effective. A long midline abdominal scar among those who had open abdominal surgery, clearly revealed that an LA had been performed. In addition, the patients were informed about the surgery, the histopathology report, and the risk of lymphedema and the consequences after LA, so the LA was easily revealed in the conversation when the measurements were taken. This may have increased the awareness of development of LLL and may therefore possibly generate a lower threshold for prescription of compression stockings. This might be a potential source of bias of the measurements.

\section{Conclusions and future perspectives:}

One year after treatment of EC, LLL develops regardless of whether lymphadenectomy was performed or not. The incidence of LLL is relatively high after lymphadenectomy but varies by more than $50 \%$ depending on the mode of assessment, i.e. volume measurement, clinical grading and patient's reports. The incidence of persistent lymphatic ascites and lymphocysts after one year is low and does not seem to constitute a clinical problem.

There seems to be a variation in agreement between the modalities assessing LLL volume measurement, clinical grading and patient's perception - indicating that measuring the development of LLL needs a 'gold standard' method to be useful in early clinical diagnostics as well as in scientific contexts. The dynamics of development of LLL postoperatively need further attention. 


\section{Disclosure of interest}

The authors report no conflicts of interest

\section{Contribution to authorship}

The study was conceptualized by PK who together with GL, EA, KS and JM designed the study. MW is the main author. PK and MW conducted the statistical analyses. All authors participated actively in conducting the study and critically revised the manuscript, approved the final version, and are accountable for all aspects of the work. 


\section{References}

1. Emons G. Significance of lymph node dissection in gynecological oncology. Oncol Res Treat 2014;37:500-504. DOI:10.1159/000366248.

2. Frost JA, Webster KE, Bryant A et al. Lymphadenectomy for the management of endometrial cancer. Cochrane Database of Syst Rev 2017 Oct 2, 10(10):CD007585. DOI: $10.1002 / 14651858$.

3. Kitchener H, Blake P, Sandercock J et al. Efficacy of systematic pelvic lymphadenectomy in endometrial cancer (MRC ASTEC trial): a randomized study. Lancet 2009;373(9658):125-136. DOI:10.1016/S0140-6736(08)61766-3

4. Benedetti Panici P, Basile S, Maneschi F et al. Systematic pelvic lymphadenectomy vs no lymphadenectomy in early-stage endometrial carcinoma: Randomized clinical trial. $J$ Natl Cancer Inst 2008;100:1707-1716. DOI:10.1093/jnci/djn397.

5. Biglia N, Librino A, Ottino MC et al. Lower limb lymphedema and neurological complications after lymphadenectomy for gynecological cancer. Int J Gynecol Cancer 2015;25: 521-525. DOI: 10.1097/IGC.0000000000000341.

6. Lindqvist E, Wedin M, Fredrikson M et al. Lymphedema after treatment for endometrial cancer - a review of prevalence and risk factors. Eur J Obstet Gynecol Reprod Biol 2017;211:112-121. DOI:10.1016/j.ejogrb.2017.02.021.

7. Dunberger G, Lindquist H, Waldenström A-C et al. Lower limb lymphedema in gynecological cancer survivors - effect on daily life functioning. Support Care Cancer 2013 21:3063-3070. DOI:10.1007/s00520-013-1879-3.

8. Biglia N, Zanfagnin V, Daniele A et al. Lower body lymphedema in patients with gynecologic cancer. Anticancer Res 2017;37(8):4005-4015.

DOI:10.21873/anticanres.11785. 
9. ESMO-ESGO-ESTRO Consensus Conference on Endometrial Cancer. https://guidelines.esgo.org/uterine-cancer/guidelines/early-stage-algorithms/ 2014 (accessed 19 May 2020).

10. Swedish National guidelines for endometrial cancer (Nationellt vårdprogram livmodercancer] (In Swedish):

https://www.cancercentrum.se/globalassets/cancerdiagnoser/gynekologi/livmoderkropps cancer/vardprogram/nationellt-vardprogram-endometriecancer.pdf 2014 and up-dated 2017 (accessed 19 May 2020).

11. National cancer institute. Surveillance, Epidemiology, and End Result Program. Cancer Stat Facts: Uterine cancer: https://seer.cancer.gov/statfacts/html/corp.html (accessed 19 May 2020).

12. Larson DM, Johnson K, Olson KA. Pelvic and para-aortic lymphadenectomy for surgical staging of endometrial cancer: morbidity and mortality. Obstet Gynecol 1992;79:998-1001.

13. Tanaka T, Ohki N, Kojima A et al. Radiotherapy negates the effect of retroperitoneal nonclosure for prevention of lymphedema of the legs following pelvic lymphadenectomy for gynecological malignancies: An analysis from a questionnaire survey. Int J Gynecol Cancer 2007;17(2):460-464. DOI:10.1111/j.15251438.2007.00869.x.

14. Brorson H. Volume measurements and follow-up.In: Greene AK, Slavin SA, Brorson H (Eds) Lymphedema. Presentation, Diagnosis and treatment. Springer International Publishing, Switzerland, 2015, pp 115-122.

15. Ghezzi F, Uccella S, Cromi A et al. Lymphoceles, lymphorrhea, and lymphedema after laparoscopic and open endometrial cancer staging. Ann Surg Oncol 2012;19:259-267. DOI:10.1245/s10434-011-1854-5. 
16. Salehi S, Åvall-Lundqvist E, Brandberg Y et al. Lymphedema, serious adverse events, and imaging 1 year after comprehensive staging for endometrial cancer: results from the RASHEC trial. Int J Gynecol Cancer 2019;29:86-93. DOI:10.1136/jgc-2018-000019.

17. Keeley V, Crooks S, Locke J et al. A Quality of life measure for limb lymphedema (LYMQOL) J Lymphoedema. 2010;5(1):26-37.

18. Wedin M, Fredrikson M, Ahlner E et al. Validation of the lymphoedema quality of life questionnaire (LYMQOL) in Swedish cancer patients, Acta Oncol, 2020;59(3):365-371. DOI:10.1080/0284186X.2019.1701199

19. Sitzia J. Volume measurement in lymphedema treatment: examination of formulae. Eur J Cancer Care 1995;4(1):11-16.

20. Sun F, Skolny MN, Swaroop MN et al. The need for preoperative baseline arm measurement to accurately quantify breast cancer-related lymphedema. Breast Cancer Res Treat 2016;157(2):229-240. DOI:10.1007/s10549-016-3821-0.

21. Hidding JT, Beurskens C.H.G, Van der Wees PJ et al. Changes in volume and incidence of lymphedema during and after treatment with docetaxel, doxorubicin, and cyclophosphamide (TAC) in patients with breast cancer. Support Care Cancer 2018;26(5):1383-1392. DOI:10.1007/s00520-017-3907-1.

22. Bruna J, Miller AJ, Beninson J. A simple clinical classification of lymphedema. Eur J Plast Surg 1999;22:404-405.

23. Landis JR, Koch, GG. The measurement of observer agreement for categorical data. Biometrics 1977;33:159-174.

24. World Health Organization. Body mass index - BMI. http://www.euro.who.int/en/health-topics/disease-prevention/nutrition/a-healthylifestyle/body-mass-index-bmi (accessed 19 May 2020). 
25. Bae HS, Lim MC, Lee JS et al. Postoperative lower extremity edema in patients with primary endometrial cancer. Ann Surg Oncol 2016;23(1):186-195.

DOI:10.1245/s10434-015-4613-1

26. Biglia N, Librino A, Ottino MC et al. Lower limb lymphedema and neurological complications after lymphadenectomy for gynecological cancer. Int J Gynecol Cancer 2015;25: 521-525. DOI:10.1097/ICG.0000000000000341.

27. Konno Y, Todo Y, Minobe S et al. A retrospective analysis of postoperative complications with or without para-aortic lymphadenectomy in endometrial cancer. Int J Gynecol Cancer 2011;21(2): 385-390. DOI:10.1097/IGC.0b013e3182094e09.

28. Hidding T, Viehoff PB, Beurskens CHG et al. Measurement properties of instruments for measuring of lymphedema: Systematic review. Phys Ther. 2016;96(12):1965-1981. DOI:10.2522/ptj.20150412.

29. Hopp EE, Osborne JL, Schneider DK et al. A prospective pilot study on the incidence of post-operative lymphedema in women with endometrial cancer. Gynecol Oncol Rep 2015;15:25-28. DOI:10.1016/j.gore.2015.12.002.

30. Schricker T, Lattermann R. Perioperative catabolism. Can J Anesth 2015; 62(2):182193. DOI:10.1007/s12630-014-0274-y.

31. Mendivil AA, Rettenmaier MA, Abaid LN et al. Lower-extremity lymphedema following management for endometrial and cervical cancer. Surg Oncol 2016;25(3):200-204. DOI:10.1016/j.suronc.2016.05.015.

32. O`Malley E, Ahern T, Dunlevy C et al. Obesity-related chronic lymphoedema-like swelling and physical function. QJ Med 2015;108(3):183-187.

DOI:10.1093/qjmed/hcu155. 
33. Yost KJ, Cheville AL, Al-Hilli MM et al. Lymphedema after surgery for endometrial cancer: Prevalence, risk factors, and quality of life. Obstet Gynecol 2014;124(2):307315. DOI:10.1097/AOG.0000000000000372.

34. Shahpar H, Atieh A, Maryam A et al. Risk factors of lymph edema in breast cancer patients. Int J Breast Cancer. 2013; 2013:641818. DOI:10.1155/2013/641818.

35. Zikan M, Fischerova D, Pinkavova I et al. A prospective study examining the incidence of asyptomatic and symptomatic lymphoceles following lymphadenectomy in patients with gynecological cancer. Gynecol Oncol 2015;137(2):291-298.

DOI:10.1016/j.ygyno.2015.02.016.

36. European Medicines Agency. ICH E6 (R1) Guidelines good clinical practice: https://www.ema.europa.eu/en/ich-e6-r2-good-clinical-practice (accessed 19 May 2020) 


\section{Legends to Tables and Figures.}

Figure 1. Flow chart of study population in the LASEC trial.

Figure 2. Volume of legs in relation to occasion of measurement and after whether lymphadenectomy was done at the surgery. Plots indicate means and bars indicate $95 \%$ confidence interval. Results of the repeated measures ANOVA are shown in the table below the diagrams.

Figure 3. BMI - adjusted volume of legs in relation to occasion of measurement and after whether lymphadenectomy was done at the surgery. Plots indicate means and bars indicate $95 \%$ confidence interval. Results of the repeated measures ANOVA are shown in the table below the diagrams.

Table 1. Demographic and clinical data of 235 women treated surgically for endometrial carcinoma with or without concomitant lymphadenectomy.

Table 2. Peri- and postoperative clinical data of 235 women treated surgically for endometrial carcinoma with or without lymphadenectomy.

Table 3. Histopathology information of 235 women treated surgically for endometrial carcinoma with or without lymphadenectomy.

Supplementary Tables

Table S1. Relative difference in leg volume between one year postoperatively and baseline and number of participants with differences categorized into three categories in 235 women treated surgically for endometrial carcinoma with or without lymphadenectomy. 
Table S2. Clinical grading of leg swelling according to Bruna et al. [22] in relation to occurrence of lymph node dissection in 235 women treated surgically for endometrial carcinoma with or without lymphadenectomy.

Table S3. Association between categories of body mass index (BMI) and clinical grading of leg swelling according to Bruna et al. [22] in 235 women treated surgically for endometrial carcinoma with or without lymphadenectomy.

Table S4. Patient's subjective perception of degree of swelling of the legs at baseline and one year postoperatively in 235 women treated surgically for endometrial carcinoma with or without lymphadenectomy.

Table S5. Association between categories of body mass index (BMI) and patient's subjective perception of degree of swelling of the legs in 235 women treated surgically for endometrial carcinoma with and without lymphadenectomy.

Table S6. Association between patient's perception of leg swelling and clinical grading of the lymphedema conducted by the lymphedema therapist. A) at baseline, and B) one year postoperatively.

Table S7. Association between patient's perception of leg swelling and A) relative increase in leg volumes one year postoperatively, and B) BMI-adjusted relative increase in leg volumes. Table S8. Association between clinical grading of lymph edema by lymphedema therapist and A) relative increase in leg volume one year postoperatively, and B) BMI adjusted relative increase in leg volume.

Table S9. Intraperitoneal lymphatic ascites accumulation and lymphocyst detected by vaginal ultrasonography in 235 women treated surgically for endometrial carcinoma with and without lymphadenectomy. 


\section{Acknowledgement}

Most of all, we express our deep gratitude to all women who unselfish participated in the trial, and to the co-workers. Without dedicated co-workers this study would not have been possible.

The LASEC trial group consisted of (in alphabetic order of the hospitals):

Blekinge Hospital, Karlskrona: Eva Rundqvist, MD, Annelie Jacobsson, RNM, Johanna Granberg, RNM.

Eksjö Highland Hospital: Lisbeth Liest, MD, Liselotte Roos, RN, Karin Norin Andersson, RPT.

Falun Hospital: Åsa Nyberg, MD, PhD, Karin Ervard, RN, Helena Johansson, RPT.

Gävle Hospital: Peter Smith, MD, PhD, Anette Henriksson, RN, Lena Larsson, Ulrika Ehn, RPT.

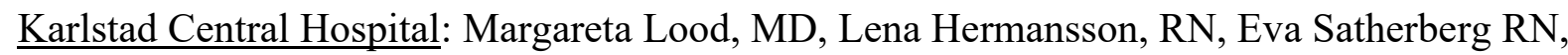
Eva Eliasson RPT.

NÄL Hospital, Trollhättan: Eva Blank, MD, PhD, Inga-Lill Martinsson, RN, Marie de-France Westerling, RPT, Eva Mattsson RPT.

Sahlgrenska University Hospital, Gothenburg: Åsa Åkesson, MD, Eva Rosén, RN, Birgitta Bååthe, RPT, Elisabeth Brodin, RPT, Matilda Möller, RPT.

Skaraborg Hospital, Skövde: Lars Hogström, MD, Maarten Buimer, MD, PhD, Agneta Johansson, RN, Eva Andersson RN, Johanna Tallbacka, RPT, Sofie Eriksson, RPT.

Sundsvall Regional Hospital: Lotta Andrèen, MD, PhD, Christine Näslund, RN, Ylva Vidgren, RPT. 
University Hospital, Linköping: Preben Kjølhede, MD, PhD, Madelene Wedin, MD, Per Rosenberg, MD, PhD, Gabriel Lindahl, MD, PhD, Linda Shosholli, RN, Åsa Rydmark Kersley, RN, MScN, Eva Ahlner, RPT.

University Hospital of Umeå: Ulrika Ottander, MD, PhD, Jenny Eklund, RN, Åsa Sandström, Annika Falk, RPT.

Uppsala University Hospital: Karin Glimskär Stålberg, MD, PhD, Charlotte Eklind, RN, Petra Strandh, RPT, Nicola Ingvast, RPT.

Varberg Hospital: Janusz Marcickiewicz, MD, PhD, Pia Andersson, RN Lotti Källman, RN, Viveka Grant-Pedersen, RPT.

Västervik Hospital: Anders Rosenmüller, MD, Carina Bergsten, RN, Camilla Dahlberg, RPT. Västmanland Hospital, Västerås: Lars Henning, MD, Andres Hess Engström, RPT.

\section{Funding details}

The study was financially supported by The Swedish Cancer Society [Cancerfonden) [grant number CAN2013/620), The Medical Research Council of Southeast Sweden [grant numbers FORSS-308611, FORSS-391311, FORSS-662141 and FORSS-858611), Uppsala-Örebro Regional Research Council [grant number LUL-349271) and unrestricted grants from the Scientific Council of the Region Halland, the County Council of Östergötland, and Linköping University. 
Table 1. Demographic and clinical data of 235 women treated surgically for endometrial carcinoma with or without concomitant lymphadenectomy.

\begin{tabular}{|c|c|c|c|c|}
\hline & \multicolumn{2}{|c|}{ Surgery including } & \multirow[b]{2}{*}{$\begin{array}{c}p- \\
\text { value* }\end{array}$} \\
\hline & & $\begin{array}{l}\text { lymph node } \\
\text { dissection } \\
(n=116)\end{array}$ & $\begin{array}{c}\text { no lymph node } \\
\text { dissection } \\
(n=119)\end{array}$ & \\
\hline \multicolumn{2}{|l|}{ Age (year) } & $66.7(9.4)$ & $66.3(9.4)$ & 0.79 \\
\hline \multicolumn{2}{|l|}{ Body mass index (kg/m²) } & $27.8(5.3)$ & $30.2(6.4)$ & $<0.01$ \\
\hline \multicolumn{2}{|l|}{ Parity } & $1.8(1.2)$ & $1.9(1.3)^{\prime}$ & 0.61 \\
\hline \multirow[t]{2}{*}{ Menopause status: } & Premenopausal & $8(6.9 \%)$ & $7(5.9 \%)$ & 0.75 \\
\hline & Postmenopausal & $108(93.1 \%)$ & $112(94.1 \%)$ & \\
\hline \multicolumn{2}{|c|}{ No. of years after menopause (postmenopausal women) } & $16.9(8.2)$ & $16.7(9.1)$ & 0.89 \\
\hline \multicolumn{2}{|c|}{ Smokers (no. of women) } & $8(6.9 \%)$ & $8(6.7 \%)$ & 0.37 \\
\hline \multirow{5}{*}{ Co-morbidity: } & Cardiovascular disease & $39(33.6 \%)$ & $41(34.5 \%)$ & 0.49 \\
\hline & Diabetes mellitus & $11(9.5 \%)$ & $18(15.1 \%)$ & 0.19 \\
\hline & Chronic pulmonary disease & $12(10.3 \%)$ & $6(5.0 \%)$ & 0.13 \\
\hline & Lower extremity varicose veins & $15(12.9 \%)$ & $12(10.1 \%)$ & 0.49 \\
\hline & Rheumatic disease & $5(4.3 \%)$ & $3(2.5 \%)$ & $0.50^{\dagger}$ \\
\hline \multirow[t]{3}{*}{ Concomitant medicatiol } & n: $\quad$ Diuretics & $15(12.9 \%)$ & $27(22.7 \%)$ & 0.05 \\
\hline & Calcium antagonists & $11(9.5 \%)$ & $17(14.3 \%)$ & 0.26 \\
\hline & NSAID & $17(14.7 \%)$ & $24(20.2 \%)$ & 0.27 \\
\hline \multirow[t]{3}{*}{ ASA group: } & I & $31(26.7 \%)$ & $44(37.0 \%)$ & $0.15^{\#}$ \\
\hline & ॥ & $72(62.0 \%)$ & $59(49.6 \%)$ & \\
\hline & III & $13(11.2 \%)$ & $16(13.5 \%)$ & \\
\hline \multicolumn{2}{|c|}{ Previously undergone laparotomy } & $32(27.6 \%)$ & $44(37.0 \%)$ & 0.12 \\
\hline \multicolumn{2}{|c|}{ Previous varicose vein surgery } & $10(8.6 \%)$ & $8(6.7)$ & 0.58 \\
\hline \multicolumn{2}{|c|}{ Previous thromboembolism in the legs } & $2(1.7 \%)$ & $6(5.0 \%)$ & $0.28 \dagger$ \\
\hline \multicolumn{2}{|c|}{ Previous treatment for leg skin infection } & $6(5.2 \%)$ & $8(6.8 \%)$ & 0.64 \\
\hline
\end{tabular}

Figures denote mean and (one standard deviation) or number of women and (per cent).

* Continuous data evaluated by means of one-way ANOVA and categorical data by means of Pearson's chisquared test ( $d f=1$ or $\left.{ }^{\#} d f=2\right)$, or $\uparrow$ Fishers exact test 
Table 2. Peri- and postoperative clinical data of 235 women treated surgically for endometrial carcinoma with or without lymphadenectomy.

\begin{tabular}{|c|c|c|c|}
\hline & \multicolumn{2}{|c|}{ Surgery including } \\
\hline & & $\begin{array}{l}\text { lymph node } \\
\text { dissection } \\
(n=116)\end{array}$ & $\begin{array}{c}\text { no lymph node } \\
\text { dissection } \\
(n=119)\end{array}$ \\
\hline \multirow[t]{3}{*}{ Hysterectomy technique (end of surgery) } & Open & $74(63.8 \%)$ & $38(31.9 \%)$ \\
\hline & Laparoscopic & $1(0.9 \%)$ & $34(28.6 \%)$ \\
\hline & Robotic & $41(35.3 \%)$ & $47(39.5 \%)$ \\
\hline \multicolumn{2}{|c|}{ Laparoscopic/robotic converted to open surgery } & $3(2.6 \%)$ & $2(1.7 \%)$ \\
\hline \multirow{2}{*}{ Mode of hysterectomy } & Simple hysterectomy & $104(89.6 \%)$ & $118(99.2 \%)$ \\
\hline & Radical hysterectomy & $12(10.3 \%)$ & $1(0.8 \%)$ \\
\hline \multicolumn{2}{|l|}{ Operation time (minutes) } & $200(83)$ & $94(51)$ \\
\hline \multicolumn{2}{|l|}{ Estimated bleeding intraoperatively (ml) } & $235(297)$ & $94(117)$ \\
\hline \multirow[t]{2}{*}{ Location of lymph node dissection } & Pelvic only & $26(22.4 \%)$ & $\mathrm{NA}$ \\
\hline & Pelvic and para-aortic & $90(77.6 \%)$ & NA \\
\hline \multicolumn{4}{|c|}{ Lower level for pelvic lymph node dissection: } \\
\hline \multirow{2}{*}{\multicolumn{2}{|c|}{$\begin{array}{l}\text { Proximal to the deep circumflex iliac artery } \\
\text { Distal to the deep circumflex iliac artery }\end{array}$}} & $103(88.8 \%)$ & NA \\
\hline & & $13(11.2 \%)$ & NA \\
\hline \multicolumn{4}{|c|}{ Upper level for para-aortic lymph node dissection } \\
\hline \multirow{2}{*}{\multicolumn{2}{|c|}{$\begin{array}{ll}\text { Inferior mesenteric artery } \\
\text { Left renal vein }\end{array}$}} & $13(14.4 \%)$ & NA \\
\hline & & $77(85.6 \%)$ & NA \\
\hline \multicolumn{4}{|l|}{ Intraoperative complications: } \\
\hline \multicolumn{2}{|l|}{ Bleeding exceeding $1000 \mathrm{~mL}$} & $2(1.7 \%)$ & $0(0 \%)$ \\
\hline \multicolumn{2}{|l|}{ Urinary tract injury } & $0(0 \%)$ & $1(0.8 \%)$ \\
\hline \multicolumn{2}{|l|}{ Vascular injury } & $2(1.7 \%)$ & $1(0.8 \%)$ \\
\hline \multicolumn{2}{|c|}{ Blood transfusion during hospital stay } & $3(2.6 \%)$ & $1(0.8 \%)$ \\
\hline \multirow[t]{5}{*}{ Classification of surgical complications * } & Clavien-Dindo grade 0 & $72(62.1 \%)$ & $98(82.4 \%)$ \\
\hline & Clavien-Dindo grade I & $22(19.0 \%)$ & $9(7.6 \%)$ \\
\hline & Clavien-Dindo grade II & $14(12.1 \%)$ & $7(5.9 \%)$ \\
\hline & Clavien-Dindo grade III & $8(6.9 \%)$ & $4(3.4 \%)$ \\
\hline & Clavien-Dindo grade IV & $0(0 \%)$ & $1(0.8 \%)$ \\
\hline \multicolumn{2}{|l|}{ Re-operated within six weeks } & $7(6.0 \%)$ & $2(1.7 \%)$ \\
\hline \multicolumn{2}{|l|}{ Adjuvant chemotherapy after surgery } & $69(59.4 \%)$ & $8(6.7 \%)$ \\
\hline \multicolumn{2}{|l|}{ Adjuvant radiotherapy after surgery } & $21(18.1 \%)$ & $12(10.1 \%)$ \\
\hline \multirow[t]{3}{*}{ Mode of adjuvant radiotherapy } & Vaginal brachytherapy & $8(38.1 \%)$ & $6(50.0 \%)$ \\
\hline & XRT & $7(33.3 \%)$ & $2(16.7 \%)$ \\
\hline & XRT + brachytherapy & $6(28.6 \%)$ & $4(33.3 \%)$ \\
\hline \multirow{2}{*}{\multicolumn{2}{|c|}{$\begin{array}{l}\text { Recurrence of cancer within one year } \\
\text { Recurrence treated with chemotherapy }\end{array}$}} & $3(2.6 \%)$ & $3(2.5 \%)$ \\
\hline & & $3(2.6 \%)$ & $0(0 \%)$ \\
\hline \multirow{3}{*}{$\begin{array}{l}\text { Recurrence treated with adjuvant } \\
\text { radiotherapy }\end{array}$} & Vaginal brachytherapy & 2 & 2 \\
\hline & XRT & 1 & 0 \\
\hline & XRT+ brachytherapy & 0 & 1 \\
\hline
\end{tabular}

Figures denote mean and (one standard deviation) or number of women and (per cent).

* Contracted Clavien-Dindo classification of postoperative complications within six weeks. XRT, external radiation therapy. 
Table 3. Histopathology information of 235 women treated surgically for endometrial carcinoma with or without lymphadenectomy.

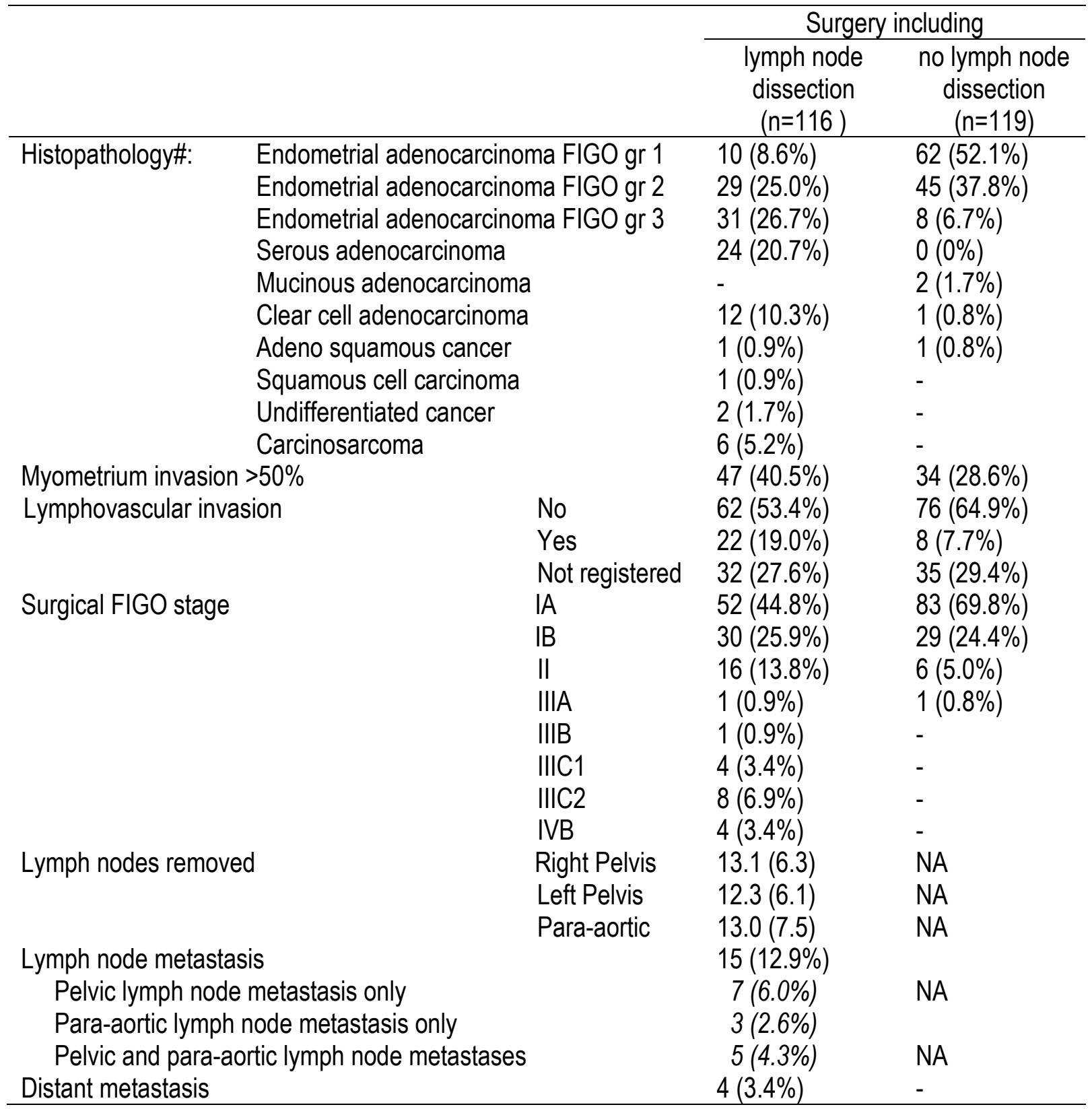

Figures denote mean and (one standard deviation) or number of women and (per cent). \# On hysterectomy specimen. 
Table S1. Relative difference in leg volume between one year postoperatively and baseline and number of participants with differences categorized into three categories in 235 women treated surgically for endometrial carcinoma with or without lymphadenectomy.

\begin{tabular}{|c|c|c|c|c|c|c|c|}
\hline \multirow[b]{2}{*}{ Location } & \multirow[b]{2}{*}{$\begin{array}{l}\text { Relative difference in } \\
\text { total leg volume }\end{array}$} & \multicolumn{2}{|c|}{$\begin{array}{l}\text { Women with lymph node dissection } \\
\qquad(\mathrm{n}=114)\end{array}$} & \multicolumn{2}{|c|}{$\begin{array}{l}\text { Women without lymph node dissection } \\
\qquad(\mathrm{n}=117)\end{array}$} & \multicolumn{2}{|c|}{ p-value (between groups) } \\
\hline & & $\begin{array}{c}\text { Crude } \\
\text { Median (range) or } \\
\mathrm{n}(\%) \\
\end{array}$ & $\begin{array}{c}\text { Adjusted for BMI } \\
\text { Median (range) or } \\
\mathrm{n}(\%)\end{array}$ & $\begin{array}{c}\text { Crude } \\
\text { Median (range) or } \\
n(\%)\end{array}$ & $\begin{array}{c}\text { Adjusted for BMI } \\
\text { Median (range) or } \\
\mathrm{n}(\%)\end{array}$ & Crude & Adjusted for BMI \\
\hline \multirow[t]{4}{*}{ Right leg } & in $\%$ & $0.6(-28.3$ to 40.5$)$ & $1.0(-11.0$ to 13.1$)$ & $0.9(-14.7$ to 28.3$)$ & $0.7(-18.7$ to 27.9$)$ & 0.552 * & 0.326 * \\
\hline & $<10 \%$ & $105(92.1 \%)$ & $107(93.9 \%)$ & $112 / 95.7 \%)$ & $114(97.4 \%)$ & $0.249 \S$ & $0.182 \S$ \\
\hline & $10-20 \%$ & $3(2.6 \%)$ & $7(6.1 \%)$ & $2(1.7 \%)$ & $2(1.7 \%)$ & & \\
\hline & $>20 \%$ & $6(5.3 \%)$ & -- & $3(2.6 \%)$ & $1(0.9 \%)$ & & \\
\hline \multirow[t]{4}{*}{ Left leg } & in $\%$ & $1.6(-29.8$ to 41.5$)$ & $0.9(-11.6$ to 32.0$)$ & $1.3(-18.6$ to 19.6$)$ & $0.9(-18.1$ to 19.2$)$ & $0.965 *$ & $0.352 *$ \\
\hline & $<10 \%$ & $99(86.8 \%)$ & $99(86.8 \%)$ & $110(94.0 \%)$ & $115(98.3 \%)$ & $0.063 \S$ & $<0.001 \S$ \\
\hline & $10-20 \%$ & $10(8.8 \%)$ & $12(10.5 \%)$ & $7(6.0 \%)$ & $2(1.7 \%)$ & & \\
\hline & $>20 \%$ & $5(4.4 \%)$ & $3(2.6 \%)$ & -- & -- & & \\
\hline \multicolumn{2}{|c|}{$p$-value volume right vs. left leg \# } & 0.228 & 0.243 & 0.513 & 0.492 & & \\
\hline \multicolumn{2}{|c|}{$p$-value frequencies right vs. left leg $\dagger$} & 0.114 & 0.061 & 0.752 & 0.999 & & \\
\hline
\end{tabular}

Relative differences in total leg volume are presented in median percent and (range) or as category with number of women and (\%).

* Mann-Whitney U-test

\# Wilcoxon matched pairs test

Due to empty cells and/or low expected numbers in a cell, the subgroups $10-20 \%$ and $>20 \%$ were gathered into one subgroup in the statistical analysis.

$\dagger$ McNemar test

$\S$ Pearson Chi-squared tests $(\mathrm{df}=1)$. 
Table S2. Clinical grading of leg swelling according to Bruna in relation to occurrence of lymph node dissection in 235 women treated surgically for endometrial carcinoma with or without lymphadenectomy.

\begin{tabular}{|c|c|c|c|c|c|c|c|c|c|}
\hline & \multirow[b]{3}{*}{ Clinical grading } & \multicolumn{4}{|c|}{ Group of women } & \multicolumn{4}{|c|}{$p$-value } \\
\hline & & \multicolumn{2}{|c|}{$\begin{array}{l}\text { with lymph node dissection } \\
(n=116)\end{array}$} & \multicolumn{2}{|c|}{$\begin{array}{l}\text { without lymph node dissection } \\
(n=118)\end{array}$} & \multicolumn{2}{|c|}{$\begin{array}{c}\text { within group \# } \\
\text { (between baseline and one year) }\end{array}$} & \multicolumn{2}{|c|}{ between groups * } \\
\hline & & Baseline & $\begin{array}{c}\text { One year } \\
\text { postoperatively }\end{array}$ & Baseline & $\begin{array}{c}\text { One year } \\
\text { postoperatively }\end{array}$ & $\begin{array}{c}\text { with lymph } \\
\text { node dissection }\end{array}$ & $\begin{array}{l}\text { without lymph } \\
\text { node dissection }\end{array}$ & at baseline & $\begin{array}{l}\text { at one-year } \\
\text { follow-up }\end{array}$ \\
\hline \multirow[t]{3}{*}{ Right leg } & Grade 0 & $107(92.2 \%)$ & $92(80.7 \%)$ & $106(89.3 \%)$ & $95(81.9 \%)$ & 0.021 & 0.099 & 0.519 & 0.816 \\
\hline & Grade 1 & $8(6.9 \%)$ & $20(17.5 \%)$ & $10(8.5 \%)$ & $14(12.1 \%)$ & & & & \\
\hline & Grade 2 & $1(0.9 \%)$ & $2(1.8 \%)$ & $2(1.7 \%)$ & $7(6.0 \%)$ & & & & \\
\hline \multirow[t]{3}{*}{ Left leg } & Grade 0 & $108(93.1 \%)$ & $91(79.8 \%)$ & $105(89.0 \%)$ & $95(82.6 \%)$ & 0.005 & 0.181 & 0.270 & 0.590 \\
\hline & Grade 1 & $8(6.9 \%)$ & $20(17.5 \%)$ & $10(8.5 \%)$ & $16(13.9 \%)$ & & & & \\
\hline & Grade 2 & -- & $3(2.6 \%)$ & $3(2.5 \%)$ & $4(3.5 \%)$ & & & & \\
\hline \multicolumn{2}{|c|}{ p-value between legs\# } & 1.000 & 1.000 & 1.000 & 0.617 & & & & \\
\hline
\end{tabular}

Due to empty cells and/or low expected number in a cell, the subgroups Grade 1 and Grade 2 were merged into one subgroup in the statistical analyses.

* Pearson Chi squared tests $(\mathrm{df}=1)$

\# McNemar test. 
Table S3. Association between categories of body mass index (BMI) and clinical grading of leg swelling according to Bruna in 235 women treated surgically for endometrial carcinoma with or without lymphadenectomy.

\begin{tabular}{|c|c|c|c|c|c|c|c|c|c|}
\hline \multirow[b]{3}{*}{ Location } & \multirow[b]{3}{*}{ Clinical grading } & \multicolumn{4}{|c|}{ Baseline } & \multicolumn{4}{|c|}{ One year postoperatively } \\
\hline & & \multicolumn{3}{|c|}{ BMI class } & \multicolumn{5}{|c|}{ BMl class } \\
\hline & & Normal weight & Overweight & Obese & $p$-value * & Normal weight & Overweight & Obese & $p$-value * \\
\hline \multirow[t]{3}{*}{ Right leg } & Grade 0 & $65(97.0 \%)$ & $72(94.7 \%)$ & $76(83.5 \%)$ & 0.005 & $56(91.2 \%)$ & $68(81.0 \%)$ & $63(74.1 \%)$ & 0.026 \\
\hline & Grade 1 & $2(3.0 \%)$ & $4(5.3 \%)$ & $12(13.2 \%)$ & & $3(4.9 \%)$ & $13(15.5 \%)$ & $18(21.2 \%)$ & \\
\hline & Grade 2 & -- & -- & $3(3.3 \%)$ & & $2(3.3 \%)$ & $3(3.6 \%)$ & $4(4.7 \%)$ & \\
\hline \multirow[t]{3}{*}{ Left leg } & Grade 0 & $65(97.0 \%)$ & $74(97.4 \%)$ & $74(81.3 \%)$ & $<0.001$ & $52(85.3 \%)$ & $70(83.3 \%)$ & $64(76.2 \%)$ & 0.319 \\
\hline & Grade 1 & $2(3.0 \%)$ & $2(2.6 \%)$ & $14(15.4 \%)$ & & $7(11.5 \%)$ & $12(14.3 \%)$ & $17(20.2 \%)$ & \\
\hline & Grade 2 & -- & -- & $3(3-3 \%)$ & & $2(3.3 \%)$ & $2(2.4 \%)$ & $3(3.6 \%)$ & \\
\hline
\end{tabular}

Due to empty cells and/or low expected number in a cell, the subgroups Grade 1 and Grade 2 were merged into one subgroup in the statistical analyses.

* Pearson Chi-squared tests $(\mathrm{df}=2)$. 
Table S4. Patient's subjective perception of degree of swelling of the legs at baseline and one year postoperatively in 235 women treated surgically for endometrial carcinoma with or without lymphadenectomy.

\begin{tabular}{|c|c|c|c|c|c|c|c|c|c|}
\hline & \multirow[b]{3}{*}{$\begin{array}{l}\text { Degree of } \\
\text { swelling }\end{array}$} & \multicolumn{4}{|c|}{ Group of women } & \multicolumn{4}{|c|}{$p$-value } \\
\hline & & \multicolumn{2}{|c|}{$\begin{array}{l}\text { with lymph node dissection } \\
(\mathrm{n}=114)\end{array}$} & \multicolumn{2}{|c|}{$\begin{array}{l}\text { without lymph node dissection } \\
(\mathrm{n}=117)\end{array}$} & \multicolumn{2}{|c|}{$\begin{array}{c}\text { within-group\# } \\
\text { (between baseline and one year) }\end{array}$} & \multicolumn{2}{|c|}{ between-groups* } \\
\hline & & $\begin{array}{c}\text { Baseline } \\
\mathrm{n}(\%)\end{array}$ & $\begin{array}{c}\text { One year follow-up } \\
n(\%)\end{array}$ & $\begin{array}{c}\text { Baseline } \\
\mathrm{n}(\%)\end{array}$ & $\begin{array}{c}\text { One year follow-up } \\
n(\%)\end{array}$ & $\begin{array}{l}\text { with lymph node } \\
\text { dissection }\end{array}$ & $\begin{array}{l}\text { without lymph } \\
\text { node dissection }\end{array}$ & at baseline & $\begin{array}{l}\text { at one yeal } \\
\text { follow-up }\end{array}$ \\
\hline \multirow[t]{4}{*}{ Right leg } & No swelling & $97(85.1 \%)$ & $65(57.0 \%)$ & $100(84.0 \%)$ & $87(74.3 \%)$ & $<0.0001$ & 0.037 & 0.918 * & $0.013^{*}$ \\
\hline & A little & $15(13.2 \%)$ & $40(35.1 \%)$ & $16(13.5 \%)$ & $27(23.1 \%)$ & & & & \\
\hline & Quite a bit & $2(1.8 \%)$ & $6(5.3 \%)$ & $2(1.7 \%)$ & $1(0.9 \%)$ & & & & \\
\hline & A lot & -- & $3(2.6 \%)$ & $1(0.8 \%)$ & $2(1.7 \%)$ & & & & \\
\hline \multirow[t]{4}{*}{ Left leg } & No swelling & $100(87.7 \%)$ & $70(61.4 \%)$ & $91(76.5 \%)$ & $81(69.2 \%)$ & $<0.0001$ & 0.095 & 0.071 * & 0.329 * \\
\hline & A little & $11(9.7 \%)$ & $32(28.1 \%)$ & $24(20.2 \%)$ & $29(24.8 \%)$ & & & & \\
\hline & Quite a bit & $2(1.8 \%)$ & $10(8.8 \%)$ & $3(2.5 \%)$ & $6(5.1 \%)$ & & & & \\
\hline & A lot & $1(0.9 \%)$ & $2(1.8 \%$ & $1(0.8 \%)$ & $1(0.9 \%)$ & & & & \\
\hline$p$-value be & ween legs $\#$ & 0.505 & 0.302 & 0.039 & 0.149 & & & & \\
\hline
\end{tabular}

Due to empty cells and/or low expected number in a cell, the subgroups Quite a bit and A lot are merged into one subgroup in the statistical betweengroup analyses. For analyses of the within-group effects, the subgroups were dichotomized into No swelling versus the swelling subgroups gathered together into one subgroup.

* Pearson chi squared test $(\mathrm{df}=2)$;

\# McNemar test. 
Table S5. Association between categories of body mass index (BMI) and patient's subjective perception of degree of swelling of the legs in 235 women treated surgically for endometrial carcinoma with and without lymphadenectomy.

\begin{tabular}{|c|c|c|c|c|c|c|c|c|c|}
\hline \multirow[b]{3}{*}{ Location } & \multirow{3}{*}{$\begin{array}{l}\text { Degree of } \\
\text { swelling }\end{array}$} & \multicolumn{4}{|c|}{ Baseline } & \multicolumn{4}{|c|}{ One year postoperatively } \\
\hline & & \multicolumn{4}{|c|}{ BMI classes } & \multicolumn{4}{|c|}{ BMI classes } \\
\hline & & Normal weight & Overweight & Obese & $p$-value * & Normal weight & Overweight & Obese & p-value * \\
\hline \multirow[t]{4}{*}{ Right leg } & No swelling & $63(94.0 \%)$ & $64(85.3 \%)$ & $70(76.9 \%)$ & 0.129 & $42(67.7 \%)$ & $61(71.8 \%)$ & $49(58.3 \%)$ & 0.312 \\
\hline & A little & $3(4.5 \%)$ & $10 / 13.3 \%)$ & $18(19.8 \%)$ & & $18(29.0 \%)$ & $18(21.2 \%)$ & $31(36.9 \%)$ & \\
\hline & Quite a bit & $1(1.5 \%)$ & $1(1.3 \%)$ & $2(2.2 \%)$ & & $2(3.2 \%)$ & $3(3.5 \%)$ & $2(2.4 \%)$ & \\
\hline & A lot & -- & -- & $1(1.1 \%)$ & & -- & $3(3.5 \%)$ & $2(2.4 \%)$ & \\
\hline \multirow[t]{4}{*}{ Left leg } & No swelling & $61(91.0 \%)$ & $62(82.7 \%)$ & $68(74.7 \%)$ & 0.159 & $37(59.7 \%)$ & $62(72-9 \%)$ & $52(61.9 \%)$ & 0.684 \\
\hline & A little & $5(7.5 \%)$ & $12(16.0 \%)$ & $18(19.8 \%)$ & & $20(32.3 \%)$ & $17(20.0 \%)$ & $24(28.6 \%)$ & \\
\hline & Quite a bit & $1(1.5 \%)$ & $1(1.3 \%)$ & $3(3.3 \%)$ & & $4(6.4 \%)$ & $5(5.9 \%)$ & $7(8.3 \%)$ & \\
\hline & A lot & -- & -- & $2(2.2 \%)$ & & $1(1.6 \%)$ & $1(1.2 \%)$ & $1(1-2 \%)$ & \\
\hline
\end{tabular}

Due to empty cells and/or low expected number in a cell, the subgroups Quite a bit and A lot were merged into one subgroup in the statistical analyses.

* Pearson Chi-squared tests $(\mathrm{df}=6)$ 
Table S6. Association between patient's perception of leg swelling and clinical grading of the lymphedema conducted by the lymphedema therapist. A) at baseline, and B) one year postoperatively.

\begin{tabular}{|c|c|c|c|c|c|c|c|}
\hline & \multirow[b]{3}{*}{ Clinical grading } & \multicolumn{6}{|c|}{ Patient's perception of swelling of the legs } \\
\hline & & \multicolumn{3}{|c|}{ Right leg } & \multicolumn{3}{|c|}{ Left leg } \\
\hline & & No swelling & Swelling & $p$-value & No swelling & Swelling & $p$-value \\
\hline \multirow[t]{2}{*}{ A } & Grade 0 & $188(95.4 \%)$ & $23(65.7 \%)$ & $<0.0001^{*}$ & $182(95.3 \%)$ & $29(70.7 \%)$ & $<0.0001^{*}$ \\
\hline & Grade $\geq 1$ & $9(4.6 \%)$ & $12(34.3 \%)$ & & $9(4.7 \%)$ & $12(29.3 \%)$ & \\
\hline \multicolumn{2}{|c|}{ Agreement } & \multicolumn{2}{|c|}{0.86} & & \multicolumn{2}{|c|}{0.84} & \\
\hline \multicolumn{2}{|c|}{ Cohen's kappa (95\%Cl) } & \multicolumn{2}{|c|}{$0.36(0.23$ to 0.48$)$} & & \multicolumn{2}{|c|}{0.31 (0.18 to 0.42$)$} & \\
\hline \multirow[t]{2}{*}{ B } & Grade 0 & $138(93.9 \%)$ & $47(59.5 \%)$ & $<0.0001^{*}$ & $143(96.6 \%)$ & $40(51.9 \%)$ & $<0.0001^{*}$ \\
\hline & Grade $\geq 1$ & $9(6.1 \%)$ & $32(40.5 \%)$ & & $5(3.4 \%)$ & $37(48.1 \%)$ & \\
\hline \multicolumn{2}{|c|}{$\begin{array}{l}\text { Agreement } \\
\text { Cohen's kappa }(95 \% \mathrm{Cl})\end{array}$} & \multicolumn{2}{|c|}{0.75} & & 0.80 & 30 & \\
\hline
\end{tabular}

* Pearson chi squared test 
Table S7. Association between patient's perception of leg swelling and A) relative increase in leg volumes one year postoperatively, and B) BMI-adjusted relative increase in leg volumes.

\begin{tabular}{|c|c|c|c|c|c|c|c|}
\hline & & \multicolumn{6}{|c|}{ Patient's perception of swelling of the legs } \\
\hline & \multirow[b]{2}{*}{ Relative increase in volume } & \multicolumn{3}{|c|}{ Right leg } & \multicolumn{3}{|c|}{ Left leg } \\
\hline & & No swelling & Swelling & $p$-value & No swelling & Swelling & $p$-value \\
\hline \multirow[t]{2}{*}{$\mathbf{A}$} & $<10 \%$ & $145(97.3 \%)$ & $69(87.3 \%)$ & $0.004 \#$ & $137(92.6 \%)$ & $69(86.3 \%)$ & $0.123^{*}$ \\
\hline & $\geq 10 \%$ & $4(2.7 \%)$ & $10(12.7 \%)$ & & $11(7.4 \%)$ & $11(13.7 \%)$ & \\
\hline & & \multicolumn{2}{|c|}{0.68} & & \multicolumn{2}{|c|}{0.65} & \\
\hline \multicolumn{2}{|c|}{ Cohen's kappa $(95 \% \mathrm{Cl})$} & \multicolumn{3}{|c|}{$0.12(0.04$ to 0.20$)$} & \multicolumn{2}{|c|}{$0.08(-0.02$ to 0.17$)$} & \\
\hline \multirow[t]{2}{*}{ B } & $<10 \%$ & $145(97.3 \%)$ & $72(92.4 \%)$ & $0.099^{*}$ & $141(95.3 \%)$ & $70(87.5 \%)$ & $0.061^{*}$ \\
\hline & $\geq 10 \%$ & $4(2.7 \%)$ & $6(7.6 \%)$ & & $7(4.7 \%)$ & $10(12.5 \%)$ & \\
\hline \multicolumn{2}{|c|}{ Agreement } & \multicolumn{2}{|c|}{0.67} & & \multicolumn{2}{|c|}{0.66} & \\
\hline \multicolumn{2}{|c|}{ Cohen's kappa $(95 \% \mathrm{Cl})$} & \multicolumn{2}{|c|}{$0.06(-0.01$ to 0.13$)$} & & \multicolumn{2}{|c|}{$0.09(0.01$ to 0.18$)$} & \\
\hline
\end{tabular}

*Pearson chi squared test

\# Fisher's exact test. 
Table S8. Association between clinical grading of lymph edema by lymphedema therapist and A) relative increase in leg volume one year postoperatively, and B) BMI adjusted relative increase in leg volume.

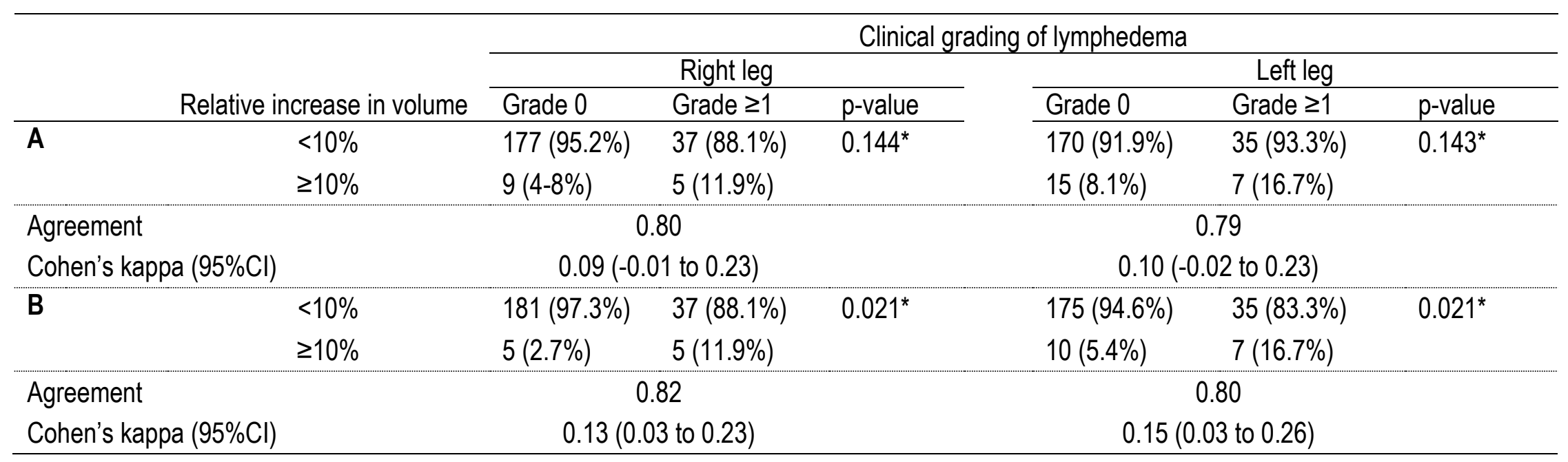

*Fisher's exact test 
Table S9. Intraperitoneal lymphatic ascites accumulation and lymphocyst detected by vaginal ultrasonography in 235 women treated surgically for endometrial carcinoma with and without lymphadenectomy.

\begin{tabular}{|c|c|c|c|c|c|}
\hline \multirow{3}{*}{$\begin{array}{l}\text { Timing of } \\
\text { examination }\end{array}$} & \multirow{3}{*}{$\begin{array}{c}\text { Occurrence of } \\
\text { lymphatic ascites or } \\
\text { lymphocele }\end{array}$} & \multicolumn{4}{|c|}{ Group of women } \\
\hline & & \multicolumn{2}{|c|}{$\begin{array}{l}\text { with lymph node dissection } \\
\qquad(\mathrm{n}=116)\end{array}$} & \multicolumn{2}{|c|}{$\begin{array}{l}\text { without lymph node dissection } \\
\qquad(\mathrm{n}=119)\end{array}$} \\
\hline & & Lymphocyst & Lymphatic ascites & Lymphocyst & Lymphatic ascites \\
\hline \multirow[t]{2}{*}{ 4-6 weeks } & Yes & $11(9.6 \%)$ & $49(42.2 \%)$ & $0(0 \%)$ & $5(4.2 \%)$ \\
\hline & No & $105(90.4 \%)$ & $67(57.8 \%)$ & $119(100 \%)$ & $114(95.8 \%)$ \\
\hline \multirow[t]{2}{*}{ Six months } & Yes & $3(2.7 \%)$ & $11(9.8 \%)$ & $0(0 \%)$ & $1(0.9 \%)$ \\
\hline & No & $109(97.3 \%)$ & $101(90.2 \%)$ & $113(100 \%)$ & $112(99.1 \%)$ \\
\hline \multirow[t]{2}{*}{ One year } & Yes & $5(4.3 \%)$ & $4(3.4 \%)$ & $0(0 \%)$ & $0(0 \%)$ \\
\hline & No & $111(95.7 \%)$ & $112(96.6 \%)$ & $118(100 \%)$ & $118(100 \%)$ \\
\hline
\end{tabular}




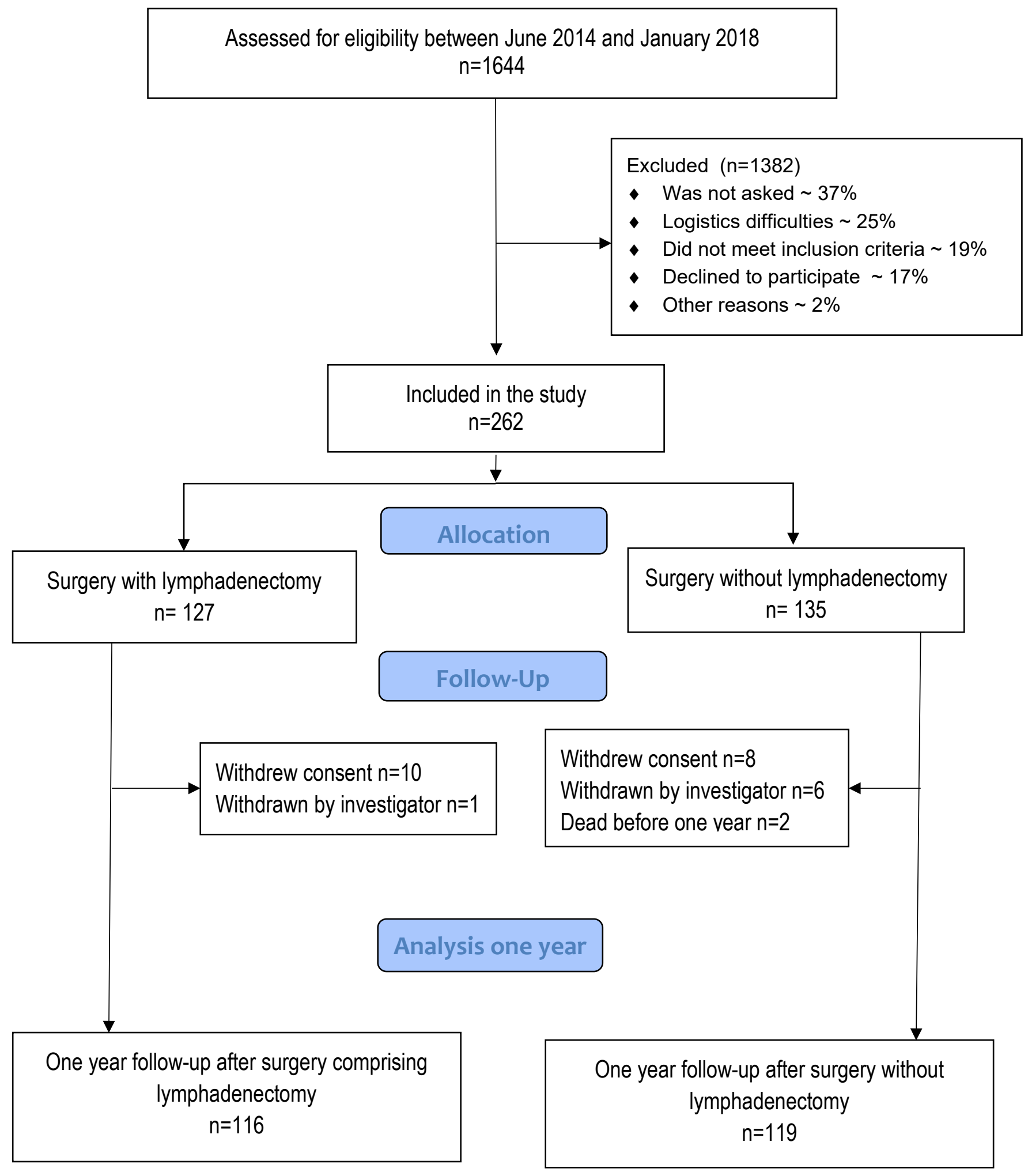

Figure 1. Flow chart of study population in the LASEC trial. 

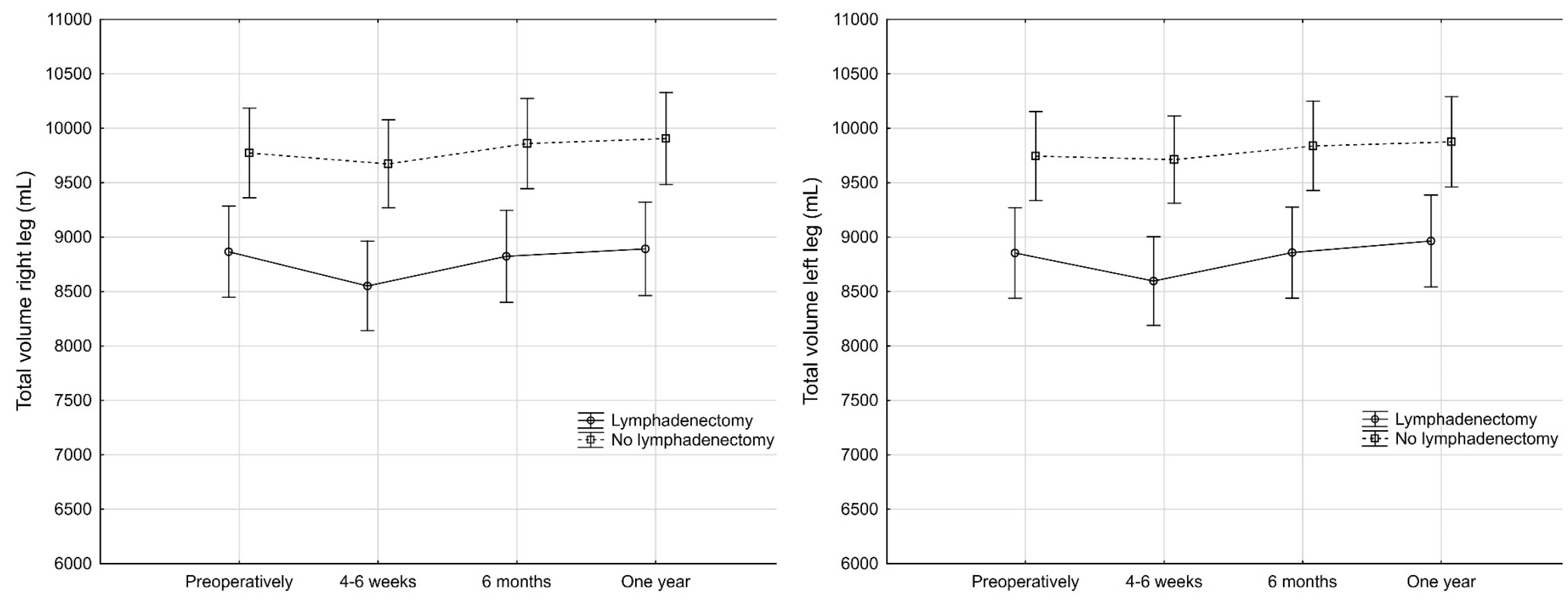

\begin{tabular}{|c|c|c|c|c|c|}
\hline \multicolumn{6}{|c|}{ Repeated measures ANOVA ( $p$-values) } \\
\hline \multicolumn{3}{|c|}{ Right leg } & \multicolumn{3}{|c|}{ Left leg } \\
\hline$<0.001$ & $<0.0001$ & 0.03 & $<0.01$ & $<0.0001$ & 0.01 \\
\hline
\end{tabular}

Figure 2. Volume of legs in relation to occasion of measurement and after whether lymphadenectomy was done at the surgery. Plots indicate means and bars indicate 95\% confidence interval. Results of the repeated measures ANOVA are shown in the table below the diagrams. 

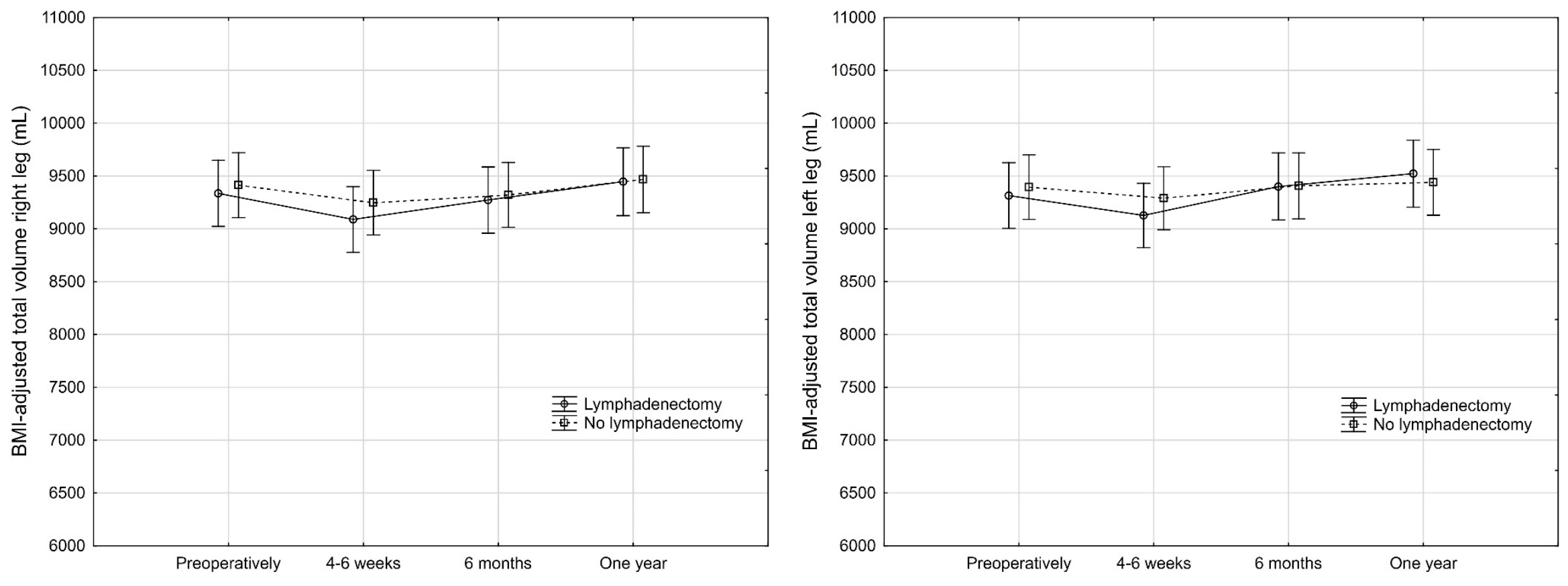

\begin{tabular}{|c|c|c|c|c|c|}
\hline \multicolumn{6}{|c|}{ Repeated measures ANOVA ( $p$-values) } \\
\hline \multicolumn{3}{|c|}{ Right leg } & \multicolumn{3}{|c|}{ Left leg } \\
\hline 0.73 & $<0.0001$ & 0.11 & 0.85 & $<0.0001$ & $<0.001$ \\
\hline
\end{tabular}

Figure 3. BMI - adjusted volume of legs in relation to occasion of measurement and after whether lymphadenectomy was done at the surgery. Plots indicate means and bars indicate 95\% confidence interval. Results of the repeated measures ANOVA are shown in the table below the diagrams. 